\title{
Droughts and climate warming desynchronize Black pine growth across the Mediterranean Basin
}

\author{
Gabriel Sangüesa-Barreda , J. Julio Camarero, Raúl Sánchez-Salguero, Emilia Gutiérrez, \\ Juan Carlos Linares, Mar Génova , Montserrat Ribas , Pedro Antonio Tíscar , José Antonio López-Sáez
}

\section{H I G H L I G H T S}

- Climate change impacts on tree growth are not homogeneous.

- A tree-ring network of 77 Mediterranean Black pine forests was analyzed.

- Contrasting growth and climate patterns were found in west vs. east forests.

- Black pine growth of east and west populations desynchronized after the 1970s.

- The loss of synchrony was linked to several and uncoupled regional droughts.

\section{A R T I C L E I N F O}

\section{Article history:}

Received 24 June 2019

Received in revised form 16 August 2019

Accepted 18 August 2019

Available online 22 August 2019

Editor: Elena Paoletti

\section{Keywords:}

Biogeography

Dendroecology

Pinus nigra

Tree rings

Species distribution
G R A P H ICA L A B S T R A C T

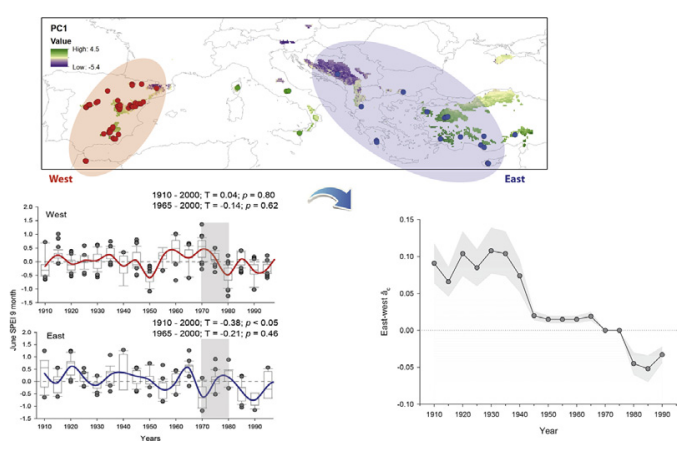

\section{A B S T R A C T}

The effects of climate change on forest growth are not homogeneous across tree species distribution ranges because of inter-population variability and spatial heterogeneity. Although latitudinal and thermal gradients in growth patterns have been widely investigated, changes in these patterns along longitudinal gradients due to the different timing and severity of regional droughts are less studied. Here, we investigated these responses in Mediterranean Black pine (Pinus nigra Arn.). We built a tree-ring width dataset comprising 77 forests (1202 trees) across the Mediterranean Basin. The biogeographical patterns in growth patterns and the relationships between growth and mean temperature, precipitation, drought and atmospheric circulations patterns (NAO -North Atlantic Oscillation-, SOI -Southern Oscillation Index- and MOI -Mediterranean Oscillation index-) were analyzed. Then, we evaluated the spatial and temporal growth synchrony between and within east and west populations. We found different growth and climate patterns in west vs. east Black pine populations, although in both regions growth was driven by similar temperature and precipitation variables. MOI significantly influenced tree growth, whilst NAO and SOI showed weaker effects. Growth of east and west Black pine populations desynchronized after the 1970s when several and uncoupled regional droughts occurred across the Mediterranean Basin. We detected a climate shift from the 1970s to the 1980s affecting growth patterns, changing growth-climate relationships, and reducing forest growth from west to east Black pine forests. Afterwards, 


\section{Introduction}

How environmental variation alters forest productivity and tree performance through time and across species' distribution ranges remains one of the pivotal uncertainties in biogeography and ecology (Thuiller et al., 2008; Walther et al., 2002). The mechanisms and strategies underlying forest responses to climate through time are complex and vary among tree species and between regions (Dorado-Liñán et al., 2019; Gazol et al., 2018), but also depend on physiological constraints related to tree ontogeny (Rabasa et al., 2013), genetic origin (Sánchez-Salguero et al., 2018) and size (Olson et al., 2018). Unravelling these complex responses requires new framework that integrate information of longterm growth and broad spatial scales of biogeographical analyses (Benito-Garzón et al., 2013).

Climate change is a complex process acting as a selective force including a pronounced rise in air temperatures, a higher frequency and severity of extreme weather events (e.g. droughts), together with higher temporal and spatial variability in precipitation (IPCC, 2014). These impacts, as a whole, act as a filter that may result in local extinctions or shifts of tree species populations (Taberlet and Cheddadi, 2002). Moreover, dissimilar impacts on tree populations may accentuate the differences between regions or subspecies spatially segregated due to long-term climatic differences (Seim et al., 2014).

The influence of climate change on regional and local drought variability might be particularly significant across the Mediterranean Basin (hereafter $\mathrm{MB}$ ), which is one of the climate change hotspots where many European tree species reach their southernmost distribution limits (Luterbacher et al., 2012). Nonetheless, a pronounced warming and higher inter-annual rainfall variability, including extreme drought events, is projected across the MB for the next decades (Meehl and Tebaldi, 2004). Indeed, the MB has experienced an increase in temperature during the 20th century which was more accentuated in the western area (Gao and Giorgi, 2008; Giorgi, 2006; Kutiel and Maheras, 1998; Rodrigo et al., 1999), and a widespread reduction in winter precipitation, except in the southeastern part, linked to changes in atmospheric circulation patterns (Dünkeloh and Jacobeit, 2003). Climatic models predict that these trends will continue throughout the $\mathrm{MB}$ (Giorgi and Lionello, 2008), as well as an increment in heavy rain episodes and temperature extremes (Goubanova and Li, 2007).

The MB has a complex and heterogeneous climatology, which is determined by its geographical location, its dimensions and the interaction of different components, i.e. regional topography, distance to mountains and coasts, and the local and general atmospheric circulation patterns. Due to its location, the climate of the MB is a transition climate between the northern temperate climate and the semi-arid climate in the south. Because of its dimensions and the atmospheric circulation patterns in the basin, there is a manifest east-west dipole, which is revealed in the negative correlations between east and west climate variables (Xoplaki et al., 2003). The MB shows a longitudinal gradient of precipitation from north-east (wet Adriatic and Ionian coasts) to south-west regions (dry south-east Spain; Maheras et al., 1999) that could uncouple regional droughts across the MB (Nicault et al., 2008) and emphasize the differences across the regional-dependent forest growth responses to climate (cf. Dorado-Liñán et al., 2019).

The significance of large-scale atmospheric circulation patterns in the biogeographical performance of tree species have been discussed for several MB forests (Dorado-Liñán et al., 2017), but mostly at local to regional scales (e.g. Esper et al., 2015; Rozas et al., 2015). The most important atmospheric circulation pattern across the MB, which establishes the east-west precipitation dipole, is characterized by the seasonal variation of the Mediterranean Oscillation (MO; Dünkeloh and Jacobeit, 2003; Maheras et al., 1999) which is also linked to the North Atlantic Oscillation (NAO; Feidas et al., 2006). The NAO modulates winter-spring precipitation and temperature across western Europe (Hurrell and Van Loon, 1997), thus affecting forest growth and productivity in the Iberian Peninsula (Camarero, 2011; Camarero et al., 2013; Madrigal-González et al., 2017).

Investigating the effects of climate on forest growth and productivity requires characterizing long-term growth responses of widely distributed tree species considering their temporal and spatial variability across the MB, and tree-ring data are one of the most used proxies for quantifying long-term tree climate sensitivity (Fritts, 2001). Largescale, severe droughts and warmer temperatures induce important growth reductions and similarities in climate sensitivity, increasing growth coherence (i.e., spatial synchrony in radial growth) within tree populations and between regions and species (cf. Shestakova et al., 2016). As a result, increasing synchrony in growth across the MB eastwest dipole may indicate a global and coupled drought stress on tree growth across different regions, tree species and populations (Sánchez-Salguero et al., 2018). However, a different drought impact on growth across the MB due to the longitudinal precipitation gradient may uncouple growth patterns which could lead to a reduced synchrony triggering adaptation to site conditions as has been reported by Dorado-Liñán et al. (2019). The prevailing mechanism (enhance or loss of spatial synchrony) for many Mediterranean tree species is still poorly known.

In this research, we focus on Black pine (Pinus nigra Arn.) forests considering its main and recognized subspecies to evaluate these issues owing to the species' wide longitudinal range in the $\mathrm{MB}$, covering wide bioclimatic gradients, from wet and relative cold areas in the north-east MB, to warm and driest in the south-west (Barbéro et al., 1998). Studies carried out in western MB Black pine populations (Spain and France) have shown that its radial growth is enhanced by prior wet and cold autumns, warm winters, and by cool-wet spring conditions of the year of growth (Amodei et al., 2013; Andreu et al., 2007; Camarero et al., 2013; Camarero et al., 2015; Génova and Fernández, 1998-1999; Linares and Tíscar, 2010, 2011; Martín-Benito et al., 2008; MartínBenito et al., 2010; Martín-Benito et al., 2011). Moreover, in the east populations (e.g. Turkey), Black pine growth showed positive and negative trends before and after the 1970s climate shift, respectively (Janssen et al., 2018), and May-June precipitation is the main climatic driver on growth (Akkemik and Aliye, 2005; Touchan et al., 2003). Despite this fragmented research, in this study, we attempt for the first time to ascertain the response of Black pine across the MB including populations distributed across the whole distribution area, under a broad temporal and geographical perspective, by using a large dendrochronological network of 77 forests and 1202 trees. Our goals are: (i) to quantify climate-growth sensitivity of Black pine Mediterranean forests during the last century; (ii) to determine the influence of large-scale atmospheric circulation on Black pine growth; and (iii) to quantify the spatial and temporal synchrony or coherence within and between tree populations and regions, as a proxy of drought impact. We hypothesize that growth patterns of Black pine would differ along the MB east-west dipole, and the differences between these regions will be magnified during the last decades due to different impacts of recent regional droughts. 


\section{Material and methods}

\subsection{Tree species and study area}

Black pine (Pinus nigra Arn.) is a long-lived, shade-intolerant conifer with a fragmented distribution area circumscribed to the MB (Barbéro et al., 1998; Enescu et al., 2016; Farjon and Filer, 2013; Appendix A. Supplementary data, Fig. A1). Traditionally Pinus nigra was considered constituted by different subspecies and varieties across the MB depending on specific morphological (Barbéro et al., 1998; Farjon and Filer, 2013) and genetic details (Giovannelli et al., 2019). This conifer inhabits mountain areas with calcareous-dolomitic substrates at mid to high elevations, usually from 800 to 1900 m a.s.l. (Barbéro et al., 1998). Black pine forms many transitional forests since it coexists with Pinus sylvestris, Pinus mugo and Pinus heldreichii at high altitudes in cold-wet sites, and forms mixed forests with Pinus halepensis and Pinus pinea at lower altitudes in warm-dry sites (Enescu et al., 2016). In general, Black pine is considered a drought-tolerant species, although has experienced dieback processes, especially at Iberian southern populations under semi-arid conditions (Camarero et al., 2018; Sánchez-Salguero et al., 2012). Black pine covers a wide latitudinal gradient ( $34^{\circ}$ to $44^{\circ}$ $\mathrm{N}, \mathrm{ca} .1000 \mathrm{~km}$ ) in the western and eastern regions (Martín-Benito et al., 2010), but the species longitudinal range is wider $\left(-5^{\circ} \mathrm{W}\right.$ to $36^{\circ} \mathrm{E}$, ca. $3650 \mathrm{~km}$; Fig. A1). The species has been widely used in reforestation due to its ecological plasticity (Cenni et al., 1998), but in this study, we only used data from native forests.

The study area encompasses the MB where we selected and sampled sites across the Black pine distribution area (Fig. A1). Mean annual temperature and precipitation in the Black pine distribution area ranges between $5^{\circ}$ to $15{ }^{\circ} \mathrm{C}$ and from 500 to $1500 \mathrm{~mm}$, respectively (Fig. A1; Enescu et al., 2016).

\subsection{Tree-ring network: field sampling and dendrochronological methods}

We collected wood samples in 33 sites from the Iberian Peninsula and Morocco (599 trees and 1171 cores). Additionally, we complemented this dataset with 44 sites (603 trees and 1120 cores) from the International Tree-Ring Databank (ITRDB) to cover widely the Iberian Peninsula, the central (Italy and east France) and east (Greece, Turkey and Cyprus) distribution area of Black pine (Table A1).

In each sampled site, a minimum of 10-12 dominant or codominant, living trees from undisturbed sites were sampled (Table A2) following dendrochronological methods (Fritts, 2001). Two wood cores per tree were taken at breast height $(1.3 \mathrm{~m})$, opposite oriented to the maximum slope, and using a 5.15-mm Pressler increment borer. The wood cores were air dried, mounted on wooden supports and progressively sanded until rings were perfectly visible through their transversal plane. Then, wood cores were visually cross-dated and measured using semiautomatic devices (LINTAB, RinnTech, Heidelberg, Germany; Velmex Inc., USA) with a $0.01 \mathrm{~mm}$ resolution. Finally, the cross-dating was verified using the COFECHA program (Holmes, 1983).

To remove the age-related trend and non-climatic signals (e.g. eventual past thinning or tree-to-tree competition), we detrended the treering width series. We used a double detrending procedure, fitting negative exponential functions followed by 30 -year long splines, which maximized the high-frequency climatic information, and minimized the non-climatic variance related to ontogenetic and local disturbances trends (Helama et al., 2004). We also applied autoregressive modeling to remove tree-ring width series autocorrelation. The resulting prewhitened or residual indices were averaged within each site using robust biweight means to obtain site chronologies or mean series of ring-width indices (TRWi). The detrending process was carried out using the ARSTAN program (Cook, 1985) and the dplR library (Bunn et al., 2016) in the R statistical language (R Development Core Team, 2018). To assess the signal quality of tree-ring width series several dendrochronological statistics were calculated (Table A2) (Fritts, 2001). We computed the first-order autocorrelation of raw width data (AC1), the mean correlation between trees (rbt), and the mean correlation among series (rbar).

The resulting chronologies covered different periods (Table A2), while those from eastern sites started before the 20th century and ended in the 1980s and 1990s, the western sites series encompassed the 2000s, but some of them ( $n=5)$, did not cover the whole 20th century period. Thus, we performed the analyses using two temporal windows. First, we used all the potential of the tree-ring network analyzing the common period 1954-1979. Second, we used only those chronologies, which covered the period from 1910s to the 1990s. Thus, we studied all the potential differences considering the whole tree-ring network, but we also explored the east-west growth responses considering longer periods.

To determine the common variance in growth among sites, we calculated a Principal Component Analyses (PCA) based on the variancecovariance matrix of the residual chronologies for the common period 1954-1979, and also for those chronologies which covered the period 1910-1990.

\subsection{Bioclimatic niche}

To define and characterize the bioclimatic niche of Black pine, we used a PCA analysis based on the correlation matrix of six bioclimatic variables retrieved from Wordclim 2.0 (http://worldclim.org/version2) at a $10 \times 10-\mathrm{km}$ resolution for the period 1970-2000 (Fick and Hijmans, 2017; Hijmans et al., 2005): precipitation regimes (precipitation of the warmest (bio_18), driest quarter (bio_17), and seasonality (bio_15)), and temperature (temperature of the warmest (bio_10), driest quarter (bio_9), and seasonality (bio_4)). We selected these variables because they showed the highest variability within the Black pine spatial distribution, and at the same time, they captured key climatic patterns for growth performance (cf. Camarero et al., 2013). This analysis was carried out extracting the information of the different bioclimatic variables within the Black pine MB distribution area according to Euforgen (http://www.euforgen.org/). Finally, the loadings of the first (PC1) and second (PC2) components of this PCA, which retained the highest common variability (61.6 and $15.8 \%$, respectively; i.e. $77.4 \%$ of the total), were extracted for the different studied populations, and for all the Black pine distribution area. We focused on the first two components because the explained variance in the third component was $<10 \%$. These analyses were conducted using the FactoMineR package in $\mathrm{R}$ (Lê et al., 2008). The results were visualized using the Factoextra package (Kassambara and Mundt, 2016).

\subsection{Defined bioclimatic regions}

We grouped the sampling sites into three bioclimatic regions West (Spain and Morocco), Centre (Italy and France) and East (Greece, Turkey and Cyprus) (Table A1) following to three different criteria: (i) the main climatic sub-regions found using temperature (Maheras and Kutiel, 1999) and precipitation data (Dünkeloh and Jacobeit, 2003), (ii) the differences found in the bioclimatic niche, and (iii) the presence of the five recognized Black pine subspecies (according to the nomenclature of Catalogue of life http://www.catalogueoflife.org/ and the IUCN red list https://www.iucnredlist.org/): subsp. salzmannii in western $\mathrm{MB}$, subsp. laricio in central $\mathrm{MB}$, and subsp. nigra, dalmatica and pallasiana in eastern MB (Table A1).

\subsection{Climate data, drought index and large-scale climatic fluctuations}

To analyze the influence of local and regional climate on growth, we used long-term (1901-2016) monthly climatic data (mean temperature and total precipitation) from the Climate Research Unit (CRU) TS 4.01. database (Mitchell and Jones, 2005). This climatic repository provides homogenized and quality-controlled data at $0.5^{\circ}$ spatial resolution for 
all sites (Harris et al., 2014). Climate time series were downloaded from the Climate Explorer of the Royal Netherlands Meteorological Institute (http://climexp.knmi.nl) for the $0.5^{\circ} \times 0.5^{\circ}$ (longitude and latitude) grids in which the study forests were located.

To analyze the impact of drought severity on growth we employed a multi-scalar drought index, the Standarized PrecipitationEvapotranspiration Index (SPEI), which was calculated using precipitation and temperature from the same CRU climate data previously described (Vicente-Serrano et al., 2010). We used the June SPEI following previous studies on Black pine both in western (Pasho et al., 2011) and eastern (Bhuyan et al., 2017; Janssen et al., 2018) populations. We considered a 9-month long scale to take into account the water stress throughout the entire growing season.

To assess spatial and temporal effects of circulation atmospheric patterns on tree radial growth given their wide spatial scale of influence (Stenseth et al., 2003), we considered the Mediterranean Oscillation index (MOI), the North Atlantic Oscillation (NAO) and the Southern Oscillation Index (SOI). The MOI is a mode of oscillation or pattern of atmospheric variability of the Mediterranean east-west gradient, and may be a reliable indicator of the differences in long-term climate variability in the dipole (Dünkeloh and Jacobeit, 2003; Palutikof, 2003). The NAO is a north-south dipole that determines the position of the Icelandic low pressure and the Azores high-pressure systems, and therefore the climatic patterns in southwestern Europe. The NAO has a strong influence on winter climate in the Iberian Peninsula (Hurrell et al., 2003). The SOI reflects the effects of the El Niño Southern Oscillation (ENSO), and it is a standardized index of large-scale pressure differences between the western and eastern tropical Pacific. The MOI has been previously linked to the differences in temperature and precipitation circulation of the eastern and western $\mathrm{MB}$ regions (Dünkeloh and Jacobeit, 2003; Maheras et al., 1999; Martín-Vide, 2002). Previous climate-growth studies in northern Spain have showed a major influence of NAO on spring conditions (Camarero, 2011; Rodó et al., 1997), and of SOI on the summer rainfall regime (Rozas et al., 2015). The MOI, NAO and SOI monthly data were downloaded from the Climate Research Unit webpage (https://crudata.uea.ac.uk/cru/data/pci.htm; Mitchell and Jones, 2005). The NAO, SOI and MOI indices were calculated as a normalized pressure differences between Gibraltar and Reykjavik, between Tahiti and Darwin (Australia), and between Gibraltar and Lod (Israel), respectively.

\subsection{Dendrochronological analyses}

To determine the influence of large-scale (atmospheric patterns) and local climate (precipitation, and temperature) on Black pine radial growth, we related tree-ring width indexed (TRWi) chronologies to monthly climate data using Pearson correlation coefficients (Fritts, 2001). Climate-growth relationships were calculated from September of the year prior to tree-ring formation up to September of the year of tree-ring formation. We also used the two first components of the PCA based on TRWi chronologies, as well as, seasonal values. Finally, the more significant climatic variables were mapped for the Black pine Mediterranean distribution.

Growth patterns were assessed for the three bioclimatic regions (West, Centre and East). We calculated moving correlations using a 20 -year temporal window from 1850 to 1999 . Additionally, we also calculated moving correlations between growth and the main climatic drivers using a 20-year temporal window from 1910 to 1990. For these analyses, we only used those chronologies that covered the entire period.

\subsection{Spatial and temporal synchrony patterns}

The synchrony assessment allowed us quantifying the tree-ring similitude within- and between- tree populations and bioclimatic regions (Shestakova et al., 2018). It also allowed us evaluating the global incidence of large-scale atmospheric patterns across the Black pine distribution area. For this analysis, we only used the tree-ring index chronologies of Black pine that covered the period 1900-1999 (Table A2). We defined spatial synchrony (â) as the presence of a common signal within and between the regions (West, Centre and East). To calculate â, we used the DendroSync package in R (Alday et al., 2018) following the methodology described in Shestakova et al. (2016). Firstly, we used the dendro-varcov function to fit eight variance-covariance mixed models of TRWi chronologies using "time" (varTime) and "bioclimatic region" (varGroup) as random and fixed terms, respectively. These arguments indicate the variable used to fit the variance-covariance matrices, and the fitted models considered both, homoscedastic and heteroscedastic structure (Alday et al., 2018). The fitted models were evaluated using restricted log-likelihood (LogLik) statistics: Akaike Information Criterion (AIC), corrected AIC (AICC) and Bayesian Information Criterion (BIC) (Burnham and Anderson, 2002). We selected the most parsimonious model, which showed the lower values of these statistics. Secondly, we estimated within- and between-region synchrony from the previously selected variance-covariance models using the sync function. We quantified the degree to which the chronologies contained a common growth signal within and between regions. Finally, we used the sync.trend function to assess synchrony over time using a 20-year moving window and a lag of 5 years, and the BIC to select the best VCOV model. Due to the low number of chronologies in the central region, we only focused on the east-west differences.

\section{Results}

\subsection{East-west Mediterranean dipole: bioclimatic variability and climate} patterns

The bioclimatic PCA showed differences in the Black pine niche across the north-south and east-west distribution ranges (Fig. 1). The PC1 was mainly related to the following bioclimatic variables: precipitation of the warmest (bio_18) and driest (bio_17) quarters, and temperature of the driest quarter (bio_9); whereas the PC2 was associated to temperature seasonality (bio_4) (see Fig. A2). The PC1 mainly represented the precipitation gradient from north-east to south-west, while the PC2 reflected the longitudinal east-west range. The sampled sites of the three bioclimatic regions showed differences mainly in winter precipitation, and spring and autumn temperatures, with higher values (precipitation and temperature) in the east than in the west region; however, in spring and autumn, precipitation and temperature were lower and higher in the east than in the west, respectively (Fig. A3).

\subsection{East-west Mediterranean dipole: growth variability}

The PCA results based on growth data (TRWi) showed noticeable differences in the three defined regions (Fig. 2). According to the PC1 (34.3\%) and PC2 (12.8\%) loadings for the common period 1954-1979, the east sites showed a lower variability (PC1 loadings ranged from -0.03 to 0.05 ) than the west sites (PC1 loadings ranged from 0.02 to 0.32 ). The west sites also showed a higher variability along the PC2 axis (PC2 loadings ranged from -0.18 to 0.20 ) than the east sites (PC2 loadings ranged from -0.10 to 0.06 ). Unsurprisingly, central populations showed intermediate positions in the PCA biplot. We found a negative and significant relationship between the PC1 loadings and the site longitude (Fig. 2b) but it was positive and significant with the site latitude (Fig. 2c), and no relationship with elevation was found (Fig. 2d). Longitudinal differences between west and east sites considering the PC1 loadings were significant $(p<0.001)$ in both, bioclimatic patterns and growth variability (Fig. A4). We found positive and negative relationships between the PC1 and site longitude considering climate and growth, respectively (Fig. A4). 

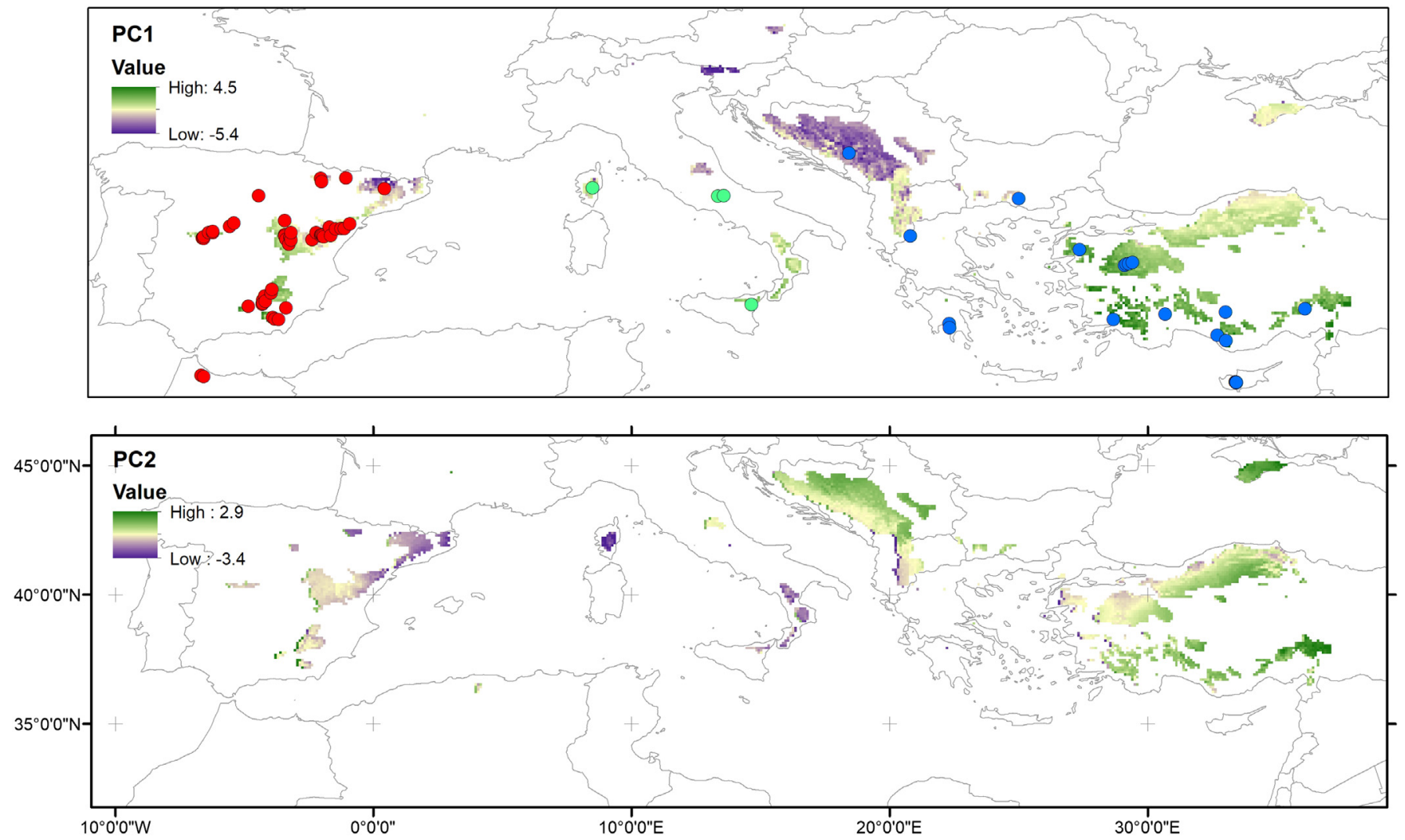

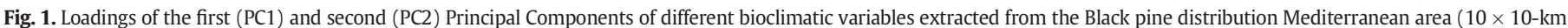

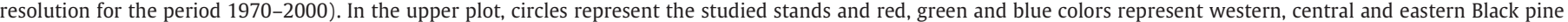
populations, respectively. (For interpretation of the references to colour in this figure legend, the reader is referred to the web version of this article.)

\subsection{Climate-growth relationships: local and large-climatic forcings}

Tree growth in the west and east regions was driven by similar temperature and precipitation variables (Fig. 3). Tree growth was mainly enhanced by wet conditions during late spring and early summer (May-June) and previous autumn (September), while warm temperatures in late winter and early spring (February and March) enhanced growth (Fig. 3; Fig. A5). On the other hand, high temperatures in the prior autumn (September and October) and late spring and early summer (May-June) negatively influenced growth (Fig. 3; Fig. A5). June and summer precipitation enhanced growth in both regions, but in the southern populations of the west sites showed less importance (Fig. A6). In general, in the east region, tree growth was more sensitive to the main climatic drivers (Fig. 3). Overall, current May and June and prior autumn-winter conditions were key drivers of growth in the west and east sites. Finally, the relationships between tree growth and SPEI were positive and in many cases significant $(p<0.05)$, although in the west region we observed a high variability (Fig. 3).

Local climate was significantly influenced by large-scale climatic forces, NAO and MOI were negatively and significantly correlated with winter, spring and autumn precipitation in the west sites and their influence was less important towards the east (Table A3). Precipitation was influenced more by NAO and MOI than temperature, although $\mathrm{NAO}$ and $\mathrm{MOI}$ were also significantly correlated with winter and spring temperature in the east and west sites, respectively. NAO and MOI effects on local climate were significantly correlated $(r=0.58 ; p<$ 0.01 ), although $\mathrm{MOI}$ influence was higher. On the other hand, in general, SOI effects were opposite to those of the NAO $(r=-0.13 ; p=0.52)$.

We found a more important response of growth to MOI than NAO and SOI (Fig. 3, A7 and A8). In the western region, February, August and summer MOI were positively and significantly correlated with
TRWi, and negatively with the previous September, December and autumn, and especially current May and spring MOI (Fig. 3). In the east populations, previous October and autumn, and current April and May MOI were positively correlated with TRWi, and February, August and winter MOI were negatively correlated. Moreover, we found different relationships in the east-west populations considering winter and summer MOI. While in western population winter and summer MOI were positively correlated with TRWi, in the eastern forests the correlations were negative and significant.

In general, we found a weak response of growth to NAO and SOI (Figs. A7 and A8). We found negative relationships between previous September NAO and TRWi in the west sites, and positive associations with February, June and previous November NAO indices (Figs. A7 and A8). Overall, in the west region, the NAO index correlated more strongly to growth in previous winter and current early-spring months. In the east sites, most correlations between TRWi and the NAO or SOI were not significant. We only found positive correlations between growth and previous October and December SOI, and negative associations with previous September SOI. Overall, SOI only showed negative correlations with TRWi for months before the year of tree-ring formation in west sites (Figs. A7 and A8).

\subsection{Growth patterns and synchrony}

In the analysis of growth synchrony, the selected model was the heteroscedastic variant of the compound symmetry (mHeCS; Table 1). The results using the second qualified model (the heteroscedastic variant of the narrow evaluation model; mHeNE) were similar (Fig. A9). Considering the period 1900-1999, the within-region growth synchrony decreased westwards (Table 2). On the other hand, we did not find differences in growth synchrony between regions. 

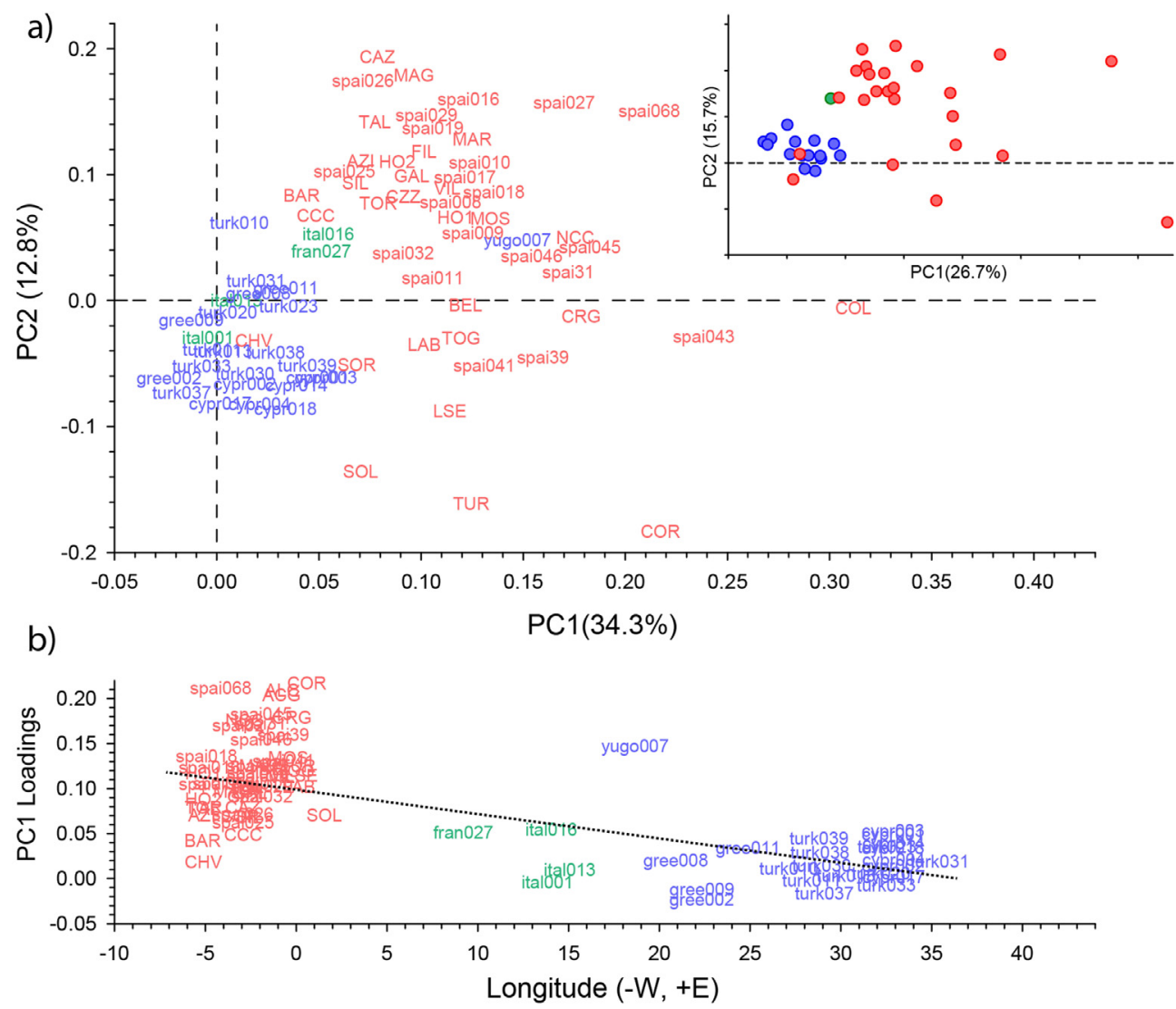

c)

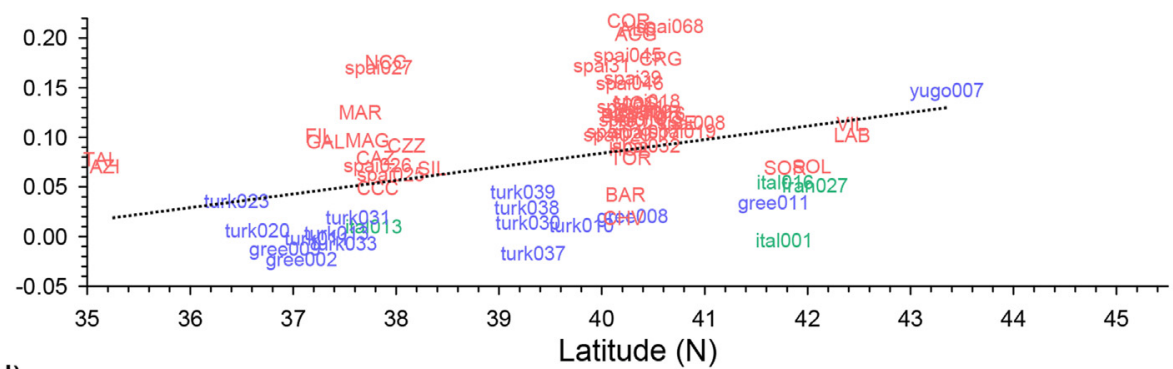

d)

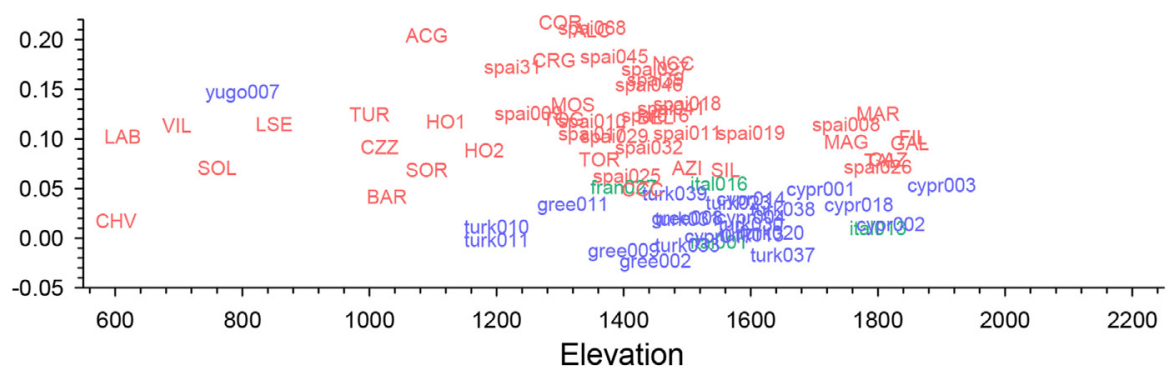

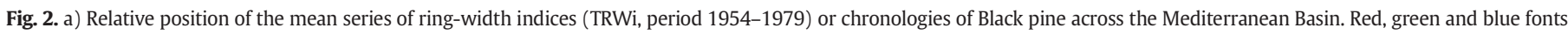

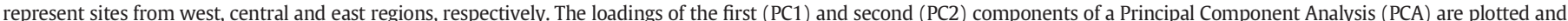

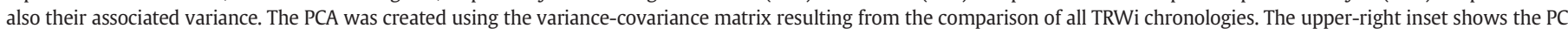

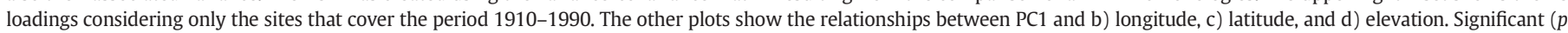

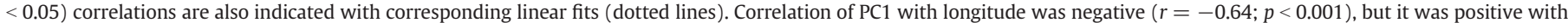
latitude $(r=0.43 ; p<0.001)$. (For interpretation of the references to colour in this figure legend, the reader is referred to the web version of this article.)

The analysis of temporal trends showed that synchrony was always higher within the east chronologies, and there were similar withingroup tendencies in the west and east regions before the 1970s. In the 1970 s, synchrony increased in the west sites, while it decreased in the east sites (Fig. 4a). Afterwards, growth synchrony in the east and west sites increased and decreased, respectively, displaying opposite trends. Analyzing the between-group east-west synchrony, we detected a reduction in the growth synchrony after the 1950s and a tipping point of changes from positive to negative synchrony values in the 1970s (Fig. 4b). The TRWi correlations in a 20-year moving window supported 

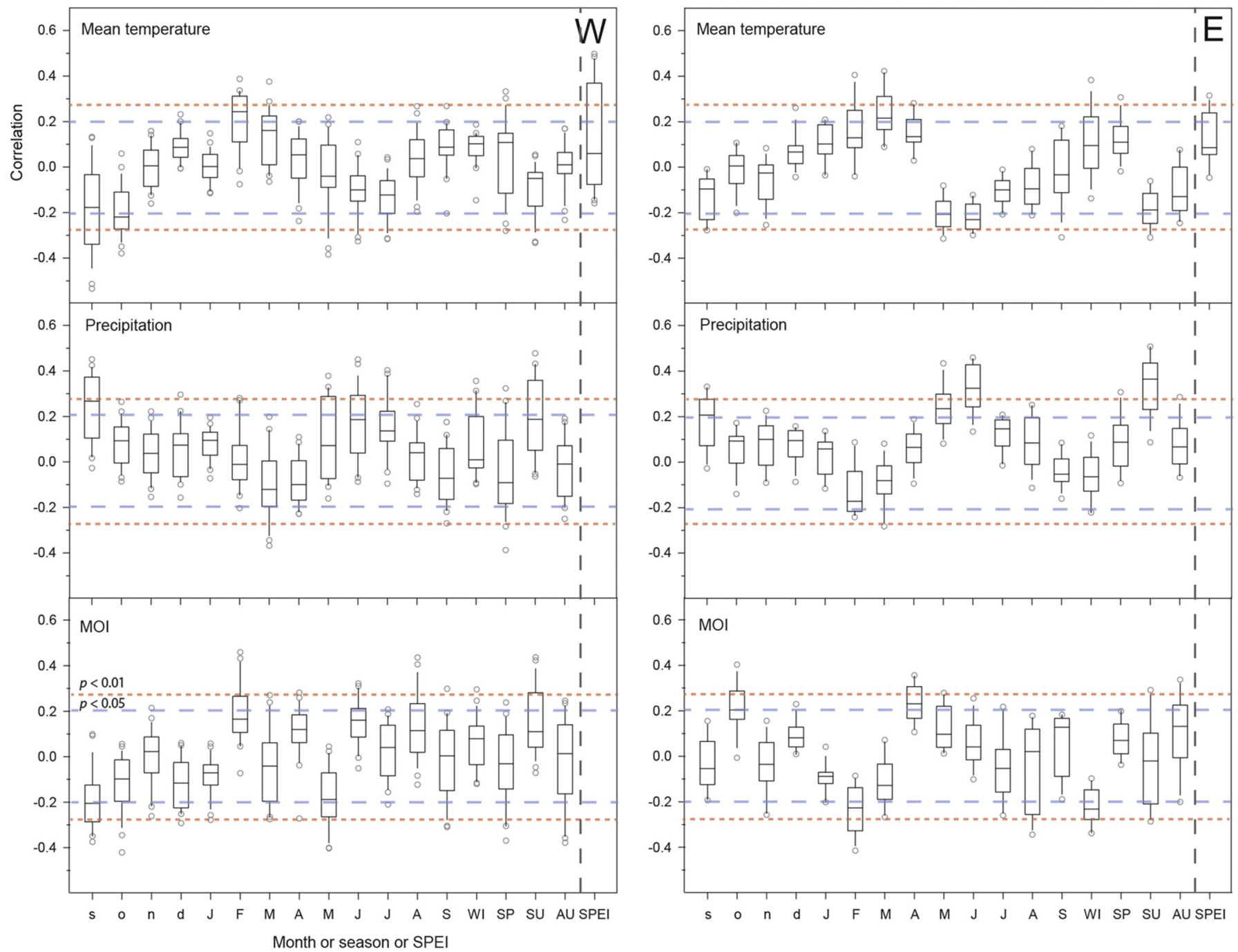

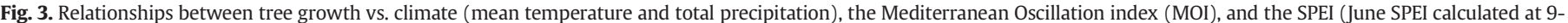

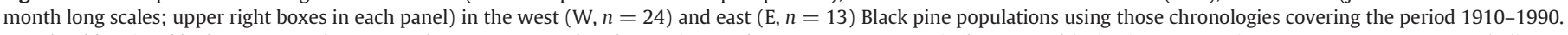

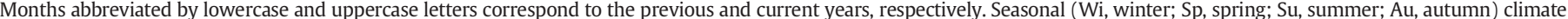

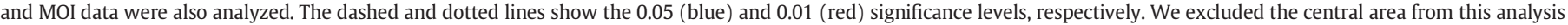
due to the low number of sites. (For interpretation of the references to colour in this figure legend, the reader is referred to the web version of this article.)

Table 1

Evaluated variance-covariance models for the studied tree-ring Black pine network according to restricted log-likelihood (LogLik) statistics: Akaike Information Criterion (AIC), corrected AIC (AICc) and Bayesian Information Criterion (BIC). The smallest AIC, AICc and BIC values represent a better fit. $N$ is the number of parameters in the fitted model and Df are degrees of freedom. The model in bold was selected. We analyzed the period 1900-1999, which encompasses a high number of chronologies in the three bioclimatic regions (west, centre and east).

\begin{tabular}{lllllll}
\hline Model & $\mathrm{N}$ & Df & AIC & AICc & BIC & LogLik \\
\hline $\begin{array}{l}\text { Homoscedastic } \\
\text { mBE }\end{array}$ & & & & & & \\
mNE & 3913 & 42 & -1691.0 & -1690.1 & -1428.0 & -1775.0 \\
mCS & 3913 & 44 & -1985.8 & -1984.8 & -1710.3 & -2073.8 \\
mUN & 3913 & 47 & -1988.5 & -1987.4 & -1694.2 & -2082.5 \\
Heteroscedastic & & & & & & \\
$\quad$ mBE & 3913 & 83 & -1691.3 & -1690.1 & -1428.0 & -1775.0 \\
mHeNE & 3913 & 87 & -2487.0 & -2485.9 & -2199.0 & -2579.0 \\
mHeCS & $\mathbf{3 9 1 3}$ & $\mathbf{8 6}$ & $\mathbf{- 2 4 8 6 . 6}$ & $\mathbf{- 2 4 8 5 . 6}$ & $\mathbf{- 2 2 0 4 . 8}$ & $\mathbf{- 2 5 7 6 . 6}$ \\
mHeUN & 3913 & 90 & -2490.0 & -2488.8 & -2183.2 & -2588.0 \\
\hline
\end{tabular}

Model abbreviations: Broad Evaluation model, mBE; Narrow Evaluation model, mNE; Compound Symmetry model, mCS; unstructured model, mUN; heteroscedastic variant of mNE, mHeNE; heteroscedastic variant of $\mathrm{mCS}, \mathrm{mHeCS}$; heteroscedastic variant of mUN, mHeUN. these results and indicated a significant $(P<0.05)$ and negative correlation between east and west sites after the 1970s (Fig. A10), while central sites were positively correlated with the west sites in the last decades. Lastly, TRWi chronologies were significantly $(P<0.05)$ associated at distances of up to ca. $550-700 \mathrm{~km}$, suggesting that this can be the

Table 2

Tree-ring width index chronologies (TRWi) synchrony $\left(\hat{a}_{\mathrm{c}}\right)$ within and between the three defined bioclimatic regions (west, centre and east) of Black pine across the Mediterranean Basin. The analyzed period is 1900-1999. Different letters indicate significant differences $(P<0.05$; Mann-Whitney tests). Values are means \pm SE.

\begin{tabular}{ll}
\hline Group & Within-group $\hat{\mathrm{a}}_{\mathrm{c}}$ \\
\hline West & $0.175 \pm 0.020 \mathrm{a}$ \\
Centre & $0.335 \pm 0.032 \mathrm{~b}$ \\
East & $0.414 \pm 0.034 \mathrm{c}$ \\
& Between-group $\hat{\mathrm{a}}_{\mathrm{c}}$ \\
Centre/west & $0.029 \pm 0.004$ \\
Centre/east & $0.045 \pm 0.006$ \\
West/east & $0.032 \pm 0.004$ \\
\hline
\end{tabular}



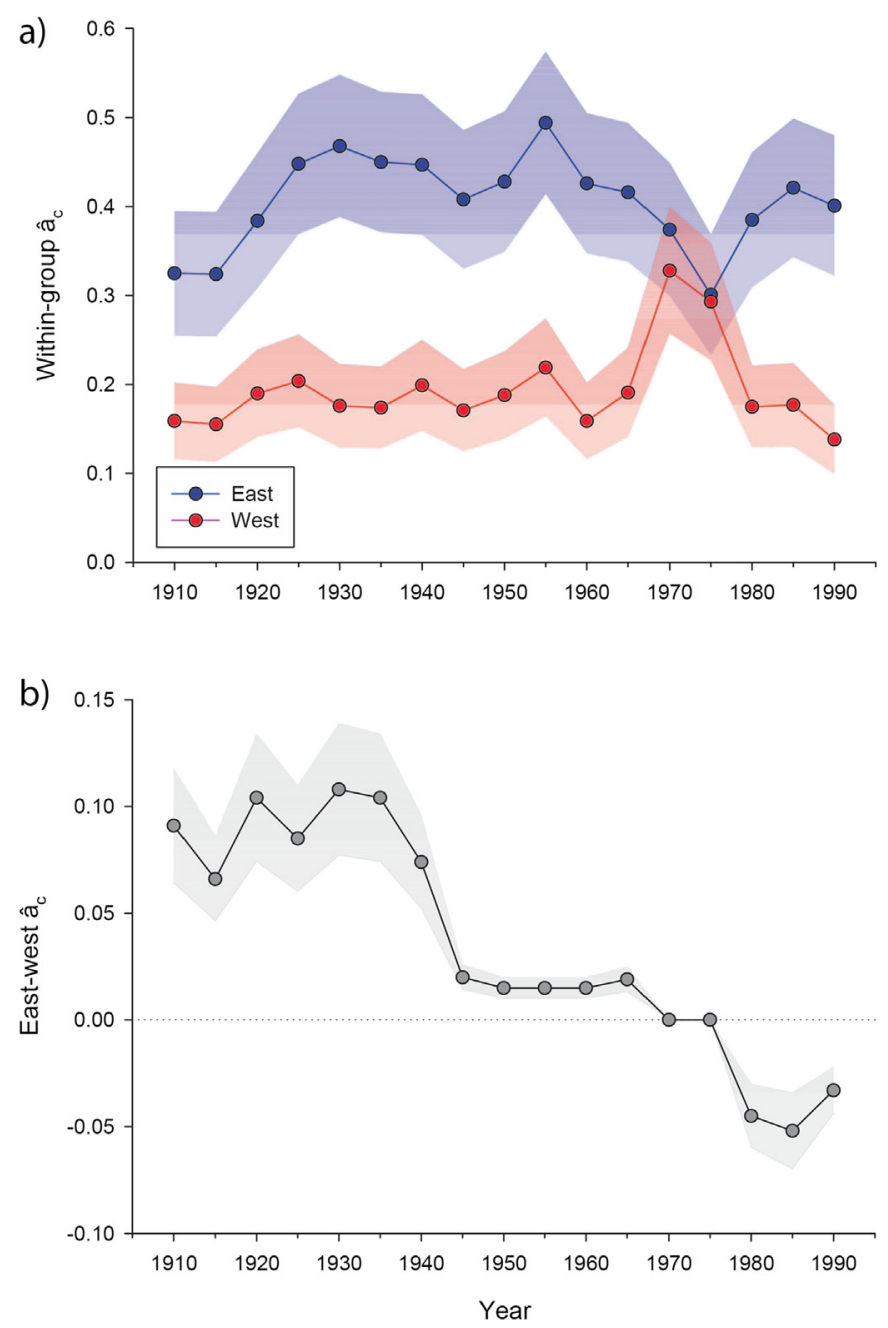

Fig. 4. Synchrony within sites considering the two main bioclimatic regions (east, $n=13$ sites; and west, $n=22$ sites). Shadow areas indicate the uncertainly ranges (standard error) (a). Synchrony among east and west study sites through time using a 20-year moving window (b). In these analyses, we only used the chronologies covering the period 1900-1999. Owing to the scarce number of sites in the central area, we excluded it from this analysis.

maximum distance of the spatial coherence in Black pine growth across the MB (Fig. A11).

\subsection{Drought severity in west vs. east sites}

Drought episodes were more pronounced in the east than in the west MB, although in both regions drought severity is intensifying after the 1970s according to the SPEI (Fig. 5).

Drought severity and timing were different in the MB west and east Black pine regions. The June drought index (SPEI) revealed that different and uncoupled drought periods were noticeable in the MB (Fig. 5). In the west sites, we observed dry conditions (low SPEI values) in the 1950 s and 1980s, after a relatively wet and cold period lasting from the 1960s to the 1970s (high SPEI values). On the other hand, in the east sites two dry periods were observed in the 1970s and 1990s. Therefore, long-term drought changes were uncoupled in the east-west distribution area of Black pine, and mainly after the second half of the 20th century.

The uncoupled regional droughts in the west and east Black pine regions were also associated with changes in key climatic variables for growth (Fig. A12). Overall, we detected different trends in the accumulated precipitation during the growing season (from previous October to current June; see Fig. A12).

\subsection{Temporal trends in climate-growth relationships}

Moving correlations between radial growth, and selected temperature, precipitation and SPEI variables showed noticeable differences in the east and west sites after the 1950s and particularly after the 1970s (Fig. 6). The SPEI showed positive correlations with growth in both regions, although after the 1970s it increased its influence on growth, especially in the west sites. May precipitation was equally important for growth in east and west sites after the 1970s, whilst correlations of growth with June precipitation showed positive and negative trends after the 1970s in west and east sites, respectively. February temperature decreased in importance for growth after the 1950s in the east sites, by contrast the west sites showed an increasing relevance of this variable for growth after the 1970s. Finally, March temperature enhanced growth similarly in west and east sites.

\section{Discussion}

The presented results support our initial hypothesis that severe and uncoupled regional droughts and local climate variability triggered the loss of growth synchrony of Black pine forests across their Mediterranean distribution range. Inter-annual variability of air temperature (IPCC, 2014) and the incidence of severe regional droughts, mainly after the 1970s climate shift towards drier conditions (Carnicer et al., 2019; Conversi et al., 2010), caused changes in the significance of climate on growth and increased the desynchronization of Black pine growth across the MB. Our study identifies multiples evidences supporting this idea. First, the analysis of key bioclimatic indicators (1970-2000) showed contrasting microclimatic environments in the north and south regions (Fig. 1), but also, and more importantly, in the east and west MB dipoles (Seim et al., 2014). Second, the analysis of inter-annual growth variability elicited the existence of different growth patterns associated to the arrangement of the studied sites along the species longitudinal range (Fig. 2). Third, the analysis of growth synchrony detected a shift or tipping point in the 1970s, when the synchrony between east and west sites became negative, climate warmed and drought severity intensified (Figs. 4 and 5). Fourth, we detected a shift in the importance of significant climate variables on Black pine growth, particularly after the 1970s (Figs. 5 and 6). In eastern MB temperatures are higher and precipitation is lower in late spring-early summer (May and June) and in late summer-early autumn (September and October), and therefore droughts are more pronounced than in western MB (Fig. 5). Our combination of biogeographical and dendroecological assessments allowed us determining the driving mechanisms of Black pine growth across the MB, and revealing the climate drivers of the observed loss of synchrony between east and west regions.

4.1. East-west Black pine populations show different long-term, interannual growth variability

The PCA results of both regions (Fig. 1) and growth variability (Fig. 2) yielded a clear separation between the east and west Black pine populations, which was in line with the climatic sub-regions previously defined (Dünkeloh and Jacobeit, 2003; Maheras and Kutiel, 1999), and mainly linked to differences in winter precipitation and summerautumn temperatures (Fig. A3). The arrangement in the Mediterranean east-west dipole appeared to be more important for high-frequency growth variability than other characteristics such as site elevation (Fig. 2), which is in agreement with previous results by Dorado-Liñán et al. (2019). These authors concluded that species adaptation to site conditions prevails over species-specific determinism in forest response to climate change. In fact, this contingency on local conditions agrees with the differentiation into subspecies across the MB widely described in Black pine (Barbéro et al., 1998). Of course, there is a common macroclimate signal across the entire Black pine distribution area. This 


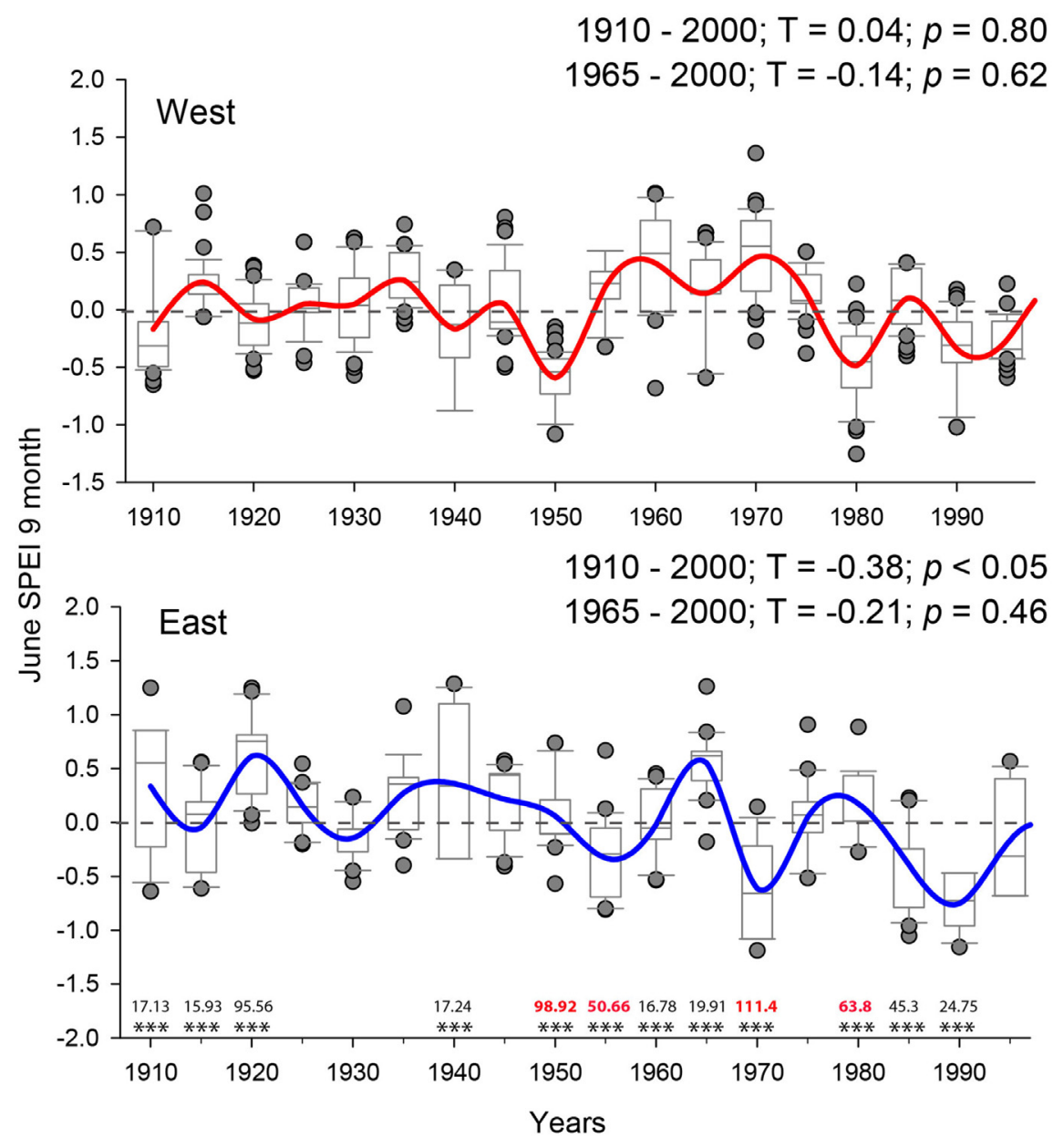

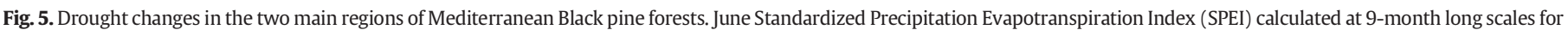

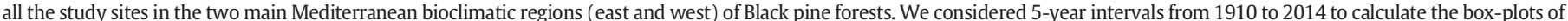

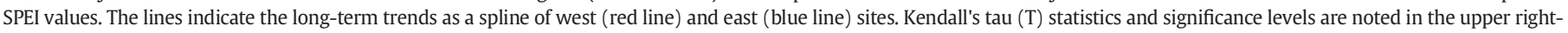

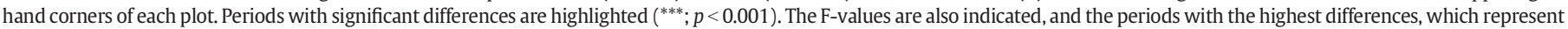
uncoupled regional droughts, are shown in red fonts. (For interpretation of the references to colour in this figure legend, the reader is referred to the web version of this article.)

is reported (1) by the first component of both PCA, which enclosed a significant percentage of common variance, and (2) by the similar influence of temperature and precipitation on growth in both eastern and western populations; we interpreted these results as the common signal at species level (Andreu et al., 2007). But at the same time there are differences in growth variability and microclimatic environment that might be related to genetic differences associated to different acclimation responses (Sánchez-Salguero et al., 2018).

\subsection{Black pine growth is enhanced by wet autumns, warm winters, and wet and cold springs}

Water availability before the start of growing season is decisive for Black pine radial growth and, in extension, for other Mediterranean pines (e.g. Andreu et al., 2007; Campelo et al., 2013). Most of the ecological niches inhabited by Mediterranean pine species are characterized by shallow soils and short springs limited by earlier water deficit if preceded by dry and warm winters. Adequate precipitation levels during winter recharge soil water reserves and positively influence subsequent growth in spring before the summer-drought onset (Camarero et al., 2013). May and June precipitation mitigate the late-spring water deficit especially in dry years, promoting the production of early and latewood (Martín-Benito et al., 2008). Our findings also remark the importance of the previous-year thermal conditions (winter) which significantly influenced growth responses the following year, and probably enhance the carbohydrate synthesis and storage in plant tissues improving wood formation (Andreu et al., 2007).

Our results agree with previous dendroecological research performed in Black pine forests from several Mediterranean countries including France (Amodei et al., 2013; Andreu et al., 2007; Lebourgeois et al., 2000), Spain (Camarero et al., 2013; Génova and Fernández, 19981999; Génova and Moya, 2012; Linares and Tíscar, 2010, 2011; Martín-Benito et al., 2008, 2010, 2011; Sánchez-Salguero et al., 2013) and Turkey (Akkemik and Aliye, 2005; Janssen et al., 2018; Touchan et al., 2003). These studies set up a high importance of winter temperature with a positive effect on growth, and a negative effect of springsummer temperature leading to enhanced evapotranspiration and drought stress (Génova and Fernández, 1998-1999; Martín-Benito et al., 2010, 2011). As Seim et al. (2014) found in several conifer species across the MB, we also observed a higher sensitivity to summer temperatures of east Black pine populations and in general a stronger climate response than their west counterparts. In this point, it should be mentioned that our study and the majority of tree-ring studies are based on sampling dominant trees whereas a recent analysis suggested that growthclimate relationships are less influenced by the choice of sampling methods than assessments of forest growth (Nehrbass-Ahles et al., 2014).

\subsection{Atmospheric circulations patterns influence Black pine growth}

The large-scale atmospheric circulation index that better explained local climate and high-frequency growth variability of Black pine in 


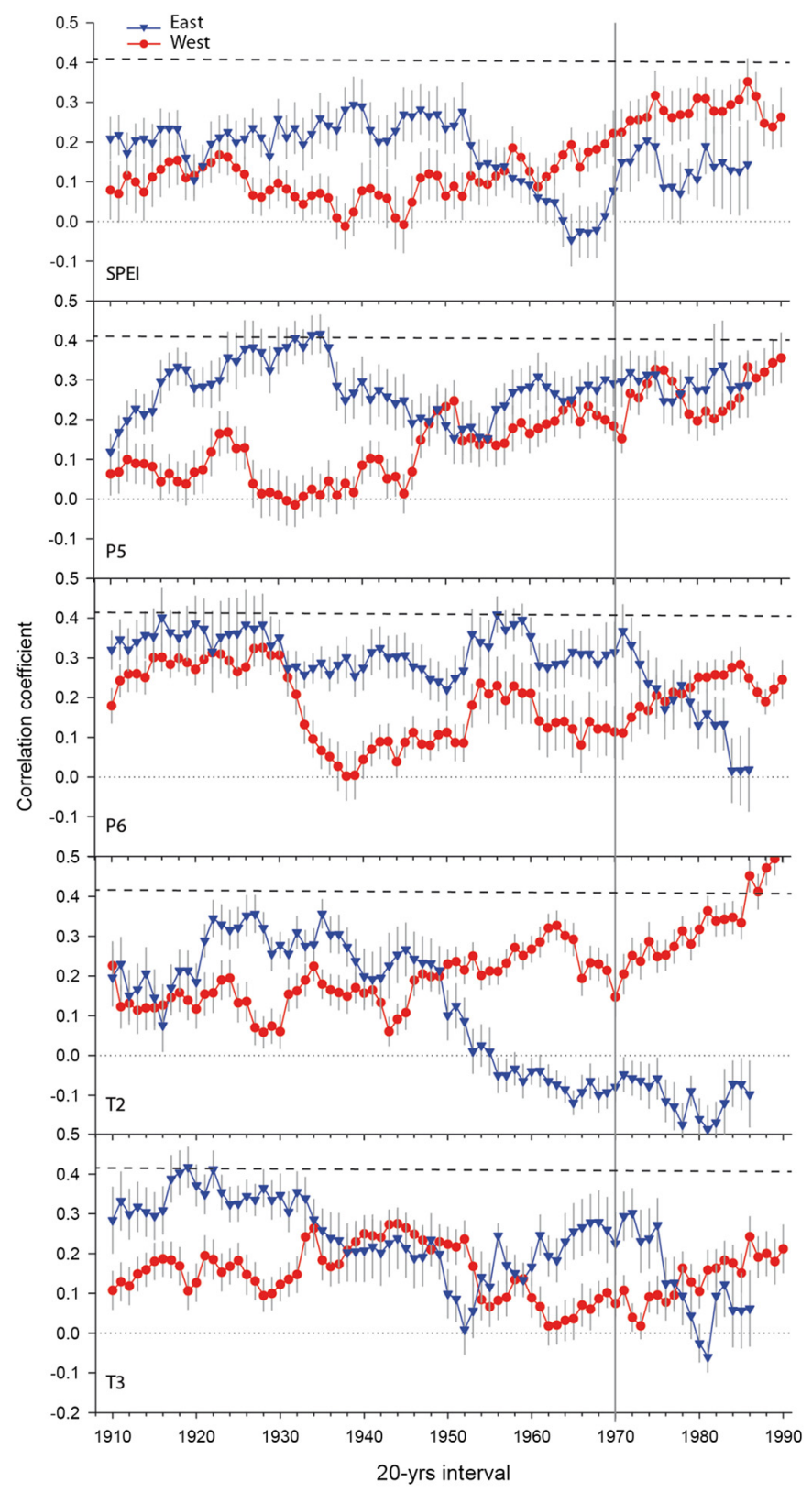

Fig. 6. 20-year running Pearson correlations between growth and the main climatic drivers for Black pine: SPEI (June SPEI calculated at 9-month long scales), May (P5) and June (P6) precipitation, and February (T2) and March (T3) temperature for the period 1910-1990. Values are arranged for the first year of each 20-year long interval. Intervals with incomplete growth data were not considered. Red and blue symbols and lines indicate mean correlations for west and east region, respectively. The standard error is also shown. Significant level $(P<0.05)$ is indicated by dashed lines. The grey vertical line indicates the climate shift of the 1970s. (For interpretation of the references to colour in this figure legend, the reader is referred to the web version of this article.)

the east-west MB populations was the MOI (Fig. 3 and Table A3). Both NAO and MOI showed a similar influence on winter-spring precipitation (Dünkeloh and Jacobeit, 2003), although MOI reflected better the dipole behaviour of the atmosphere in the MB (Criada-Aldeanueva and SotoNavarro, 2013; Xoplaki et al., 2003). Negative phases of MOI and NAO, i.e. low differences in the pressure at the two stations, promoted wet springs and winters in southwestern MB and north Africa, while winters were warmer in the eastern MB (Table A3). Previous studies found strong links between $\mathrm{MOI}$ negative phases and anomalous wet conditions over the central/western MB and hence negative correlations with winter and spring precipitation (Criada-Aldeanueva and SotoNavarro, 2013). Moreover, in line with our results, precipitation anomalies linked to extreme positive or negative MOI phases has been observed only in a reduced area of the MB (Criada-Aldeanueva and Soto-Navarro, 2013). Despite the local climate influence on growth was quite similar in both regions, MOI captured the local climate differences in the east-west dipole and also the indirect effects on growth as result of different atmospheric pressure patterns that at long-term leaded the existence of different subspecies. The use of MOI in ecology is still scarce despite previous climatic studies have indicated the suitability of MOI to assess the behavior of climate in the MB (Dünkeloh and Jacobeit, 2003; Maheras et al., 1999; Martín-Vide, 2002), especially on precipitation variations (Criada-Aldeanueva and Soto-Navarro, 2013).

Diverse researches have pointed out positive relationships between forest growth and winter NAO in the western MB (Camarero, 2011; Camarero et al., 2013; Chen et al., 2015). However, in Black pine, taking into consideration all sites $(n=77)$, and the distribution-wide analyses, we did not find a significant and robust NAO signal. Nevertheless, the 1970s tipping point or climate shift towards drier conditions has been previously linked to changes in the NAO and a weakening of the Atlantic Ocean overturning circulation (Caesar et al., 2018). These atmospheric changes in winter affect precipitation and determine the soil water availability for the next growing season, especially in the western MB sites (Camarero, 2011). Such late-winter soil moisture determines the annual tree radial growth, whose rates usually peak in spring (Camarero et al., 2013). In consequence, despite the lack of major evidences about the influence of atmospheric patterns on the year-toyear growth variability, large-climatic patterns may have a decisive incidence on the long-term growth trends, as previous studies indicated (e.g. Dorado-Liñán et al., 2017, 2019; Piovesan and Schirone, 2000).

\subsection{Severe and uncoupled regional droughts after the 1970s reduced growth synchrony}

Abrupt changes in growth synchrony are usually connected to the influence of major climate drivers such as droughts, particularly in arid regions as most of the MB (Shestakova et al., 2016). Severe droughts during important growth phases (spring) or prior seasons (winter) induce deep growth reductions in Mediterranean tree species (Camarero et al., 2015, 2018). Uncoupled drought regimes in the east and west MB regions caused a progressively uncoupling of Black pine growth after the 1950s, but especially after the 1970s (Fig. 4b). On the other hand, the 1970s climate shift towards drier conditions also induced changes in the growth-climate relationships (Fig. 6). Warmer winter and spring conditions may provoke an earlier onset of cambial activity, inducing a longer growing season, and rising growth rates whenever water availability is not too low (Begum et al., 2013). In light of our results, we observed an increasing growth dependence on most of the key climate variables, including SPEI, in west sites (Fig. 6), which suggests higher growth sensitivity to climate due to drier conditions. This result is in line with a recent study, which reported an increase of the importance of SPEI and other climate drivers for growth in several Spanish conifers, included Black pine (Shestakova et al., 2016). Notably, we observed a diminishing growth dependence on June precipitation and February temperature in the east sites, suggesting a growth shift towards a higher importance of May precipitation and January temperature (Fig. 6), and thus indicating divergent regional growth dynamics. Although the $\mathrm{MB}$ has experienced a conspicuous warming after the 1950s (IPCC, 2014), the dimensions of temperature changes and their impacts on growth are contingent on local conditions. More importantly, the changes in the influence of the main climate variables related to growth and the loss of synchrony seems in line with the increase in severity and frequency of regional droughts and the increase in air temperature as observed in Mediterranean forests (Gazol et al., 2018). Shestakova et al. (2016) also observed an increase in growth synchrony in Eurasian different conifer forests due to a higher drought 
severity after the 1950s, although they noted that regional components were also relevant as we evidenced here.

The climate shift of the 1970s towards drier conditions was characterized by a transition from cool-wet to warm-dry conditions linked to changes in the winter atmospheric circulation and NAO phases (Hurrell, 1996). In line with our results, a recent study has pointed out the climatic shift in the 1970s (east MB) and 1980s (west MB) and investigated its causes, which we associate with the loss of growth synchrony (Carnicer et al., 2019). In Black pine populations from Turkey, negative growth trends have been reported after the 1970s, which were highly correlated with the increase in temperature and drought in summer (Janssen et al., 2018). Andreu et al. (2007) suggested a higher growth synchrony in Iberian pine forests during the second half of the 20th century due to harsher climate conditions. Other authors have pointed out an increase in climatic extreme events during the last 50 years in Spain (Manrique and Fernandez-Cancio, 2000), which agrees with the observed increase in pointer years in the west region (Génova, 2000). In the same way West European beech and oak populations displayed more negative growth trends than eastern populations and these negative growth trends were exacerbated after summer drought intensified in the 1980s (Dorado-Liñán et al., 2017). In fact, the regional droughts in the 1970s and 1980s probably outweighed the positive growth trends found before across the MB.

In the west sites, the growth synchrony was exacerbated in the 1970s (Fig. 4) while the more severe drought was in the 1980s (Fig. 5), although probably affected growth since the late 1970s, when east-west correlations started to be negative. The slight uncoupling between drought and the increments in growth synchrony in the west sites may be also explained by the use of a 20 -year window in this analysis. Possibly, the impact of the 1980s drought on growth, after years of favorable weather conditions, triggered different responses within each $\mathrm{MB}$ region, resulting in a loss of synchrony afterwards. This is in agreement with the high growth variability between sites found in the west as compared to the east region (see Fig. 2).

4.5. Mediterranean Black pine populations and longitudinal precipitation gradient in a context of warmer and drier climate conditions

Climate impacts on Mediterranean tree growth populations may be dissimilar, because some species prove contrasting east-west responses to climatic variability across the MB (Dorado-Liñán et al., 2017, 2019; Seim et al., 2014). It is expected that due to the shorter latitudinal range in relation to the longitudinal gradient, the spatial variability in precipitation may attain a higher importance than temperature gradients. In this sense, significant associations between Black pine TRWi chronologies were found at distances up to ca. $550-700 \mathrm{~km}$, and similar results were found in the MB considering other pine species (Richter et al., 1991; Rolland, 2002; Seim et al., 2014; Shestakova et al., 2016). Therefore, our results, as well as previous research in other Mediterranean pine species, ratify the importance of regional climatic components, mainly precipitation and drought constraints on growth. Probably, these differences were also magnified by the complex topography in Mediterranean mountains (Linares and Tíscar, 2011).

The longitude-related differences of Black pine growth were linked to those previously observed along latitudinal gradients, not only in the west populations, which have showed die-back events and negative growth trends in the last decades (Carnicer et al., 2011; SánchezSalguero et al., 2012), but also in the eastern populations (Janssen et al., 2018). The higher frequency of negative growth years in the west populations could be associated to more severe regional droughts across Iberian Peninsula (Gazol et al., 2018).

Therefore, and in the light of our results, climate warming may lead to multiple consequences for Mediterranean forests. On one hand, the loss of tree vigor and an increase in the mortality rates in southern populations due to the lack of water availability associated to the increase in regional droughts in the second half of the 20th century (Camarero et al., 2018). On the other hand, there is an increasing loss of growth synchrony at the longitudinal edges of distribution of Mediterranean tree species as a result of multiple and uncoupled regional droughts, although major and global droughts and global climate warming could induce a recovery of growth synchrony across the MB. Therefore, if the climatic patterns keep on as in the last decades, we can find a complex geographical mosaic of species provenance and population-specific growth responses across latitudinal and longitudinal ranges (sensu Sánchez-Salguero et al., 2018).

\section{Conclusions}

To conclude, our study established multiple evidences of how local and regional climate variables, atmospheric patterns and droughts influence Black pine growth across the MB considering the east-west climate dipole. The MOI explained high-frequency growth variability of Black pine along the east-west MB dipole. The assessment of treegrowth variability across its longitudinal distribution range revealed a shift in the 1970s coincident with severe regional droughts reducing tree-ring growth differently in west and east Black pine MB populations. This climate shift towards drier conditions desynchronized growth of east and west Black pine populations. To understand how regional and local climate forcing influence forest growth is fundamental to consider the whole biogeographical area and bioclimatic variability of tree species.

\section{Acknowledgements}

We acknowledge funding by the projects FunDiver (CGL201569186-C2-1-R), COMOREADAPT (CGL2013-48843-C2-1-R), CANOPEE (Interreg V-A POCTEFA 2014- 2020-67 FEDER funds) (EFA028/15) and the EU project FORMAT (Ref. ENV4-CT97-0641). GSB and RSS are supported by Spanish Ministry of Economy, Industry and Competitiveness Postdoctoral grants (FJCI 2016-30121 and IJCI-2015-25845, respectively; FEDER funds).

\section{Declaration of competing interest}

The authors declare no conflict of interests.

\section{Appendix A. Supplementary data}

Supplementary data to this article can be found online at https://doi. org/10.1016/j.scitotenv.2019.133989.

\section{References}

Akkemik, U., Aliye, A., 2005. Reconstruction (1689-1994 AD) of April-August precipitation in the southern part of central Turkey. Int. J. Climatol. 25, 537-548.

Alday, J.G., Shestakova, T.A., Resco de Dios, V., Voltas, J., 2018. DendroSync: an R package to unravel synchrony patterns in tree-ring networks. Dendrochronologia 47, 17-22.

Amodei, T., Guibal, F., Fady, B., 2013. Relationships between climate and radial growth in black pine (Pinus nigra Arnold ssp. salzmannii (Dunal) Franco) from the south of France. Ann. For. Sci. 70, 41-47.

Andreu, L., Gutiérrez, E., Macias, M., Ribas, M., Bosch, O., Camarero, J.J., 2007. Climate increases regional tree-growth variability in Iberian pine forests. Glob. Chang. Biol. 13, 804-815.

Barbéro, M., Loisel, R., Quézel, P., Richardson, D.M., Romane, F., 1998. Pines of the Mediterranean Basin. Richardson DM (ed) Ecology and Biogeography of Pinus. Cambridge University Press, Cambridge, UK, pp. 153-170.

Begum, S. Nakaba, S., Yamagishi, Y., Oribe, Y., Funada, R., 2013. Regulation of cambial activity in relation to environmental conditions: understanding the role of temperature in wood formation of trees. Physiol. Plant. 147, 46-54.

Benito-Garzón, M., Ruiz-Benito, P., Zavala, M.A., 2013. Interspecific differences in tree growth and mortality responses to environmental drivers determine potential species distributional limits in Iberian forests. Glob. Ecol. Biogeogr. 22, 1141-1151.

Bhuyan, U., Zang, C., Menzel, A., 2017. Different responses of multispecies tree ring growth to various drought indices across Europe. Dendrochronologia 44, 1-8.

Bunn, A., Korpela, M., Biondi, F., Campelo, F., Mérian, P., Qeadan, F., Zang, C., 2016. dplR: Dendrochronology Program Library in R. R Package Version 1.6.4.

Burnham, K.P., Anderson, D.R., 2002. Model Selection and Multimodel Inference. Springer, NewYork. 
Caesar, L., Rahmstorf, S., Robinson, A., Feulner, G., 2018. Observed fingerprint of a weakening Atlantic Ocean overturning circulation. Nature 556, 191-196.

Camarero, J.J., 2011. Direct and indirect effects of the North Atlantic oscillation on tree growth and forest decline in northeastern Spain. In: Vicente-Serrano, S.M., Trigo, R.M. (Eds.), Hydrological, Socioeconomic and Ecological Impacts of the North Atlantic Oscillation in the Mediterranean Region. Advances in Global Change Research vol. 46. Springer, pp. 129-152.

Camarero, J.J., Manzanedo, R.D., Sanchez-Salguero, R., Navarro-Cerrillo, R.M., 2013. Growth response to climate and drought change along an aridity gradient in the southernmost Pinus nigra relict forests. Ann. For. Sci. 70, 769-780.

Camarero, J.J., Gazol, A., Tardif, J.C., Conciatori, F., 2015. Attributing forest responses to global-change drivers: limited evidence of a $\mathrm{CO}_{2}$-fertilization effect in Iberian pine growth. J. Biogeogr. 42, 2220-2233.

Camarero, J.J., Gazol, A., Sangüesa-Barreda, G., Cantero, A., Sánchez-Salguero, R., SánchezMiranda, A., Granda, E., Serra-Maluquer, X., Ibáñez, R., 2018. Forest growth responses to drought at short- and long-term scales in Spain: squeezing the stress memory from tree rings. Front. Ecol. Evol. 6, 1-11.

Campelo, F., Vieira, J., Nabais, C., 2013. Tree-ring growth and intra-annual density fluctuations of Pinus pinaster responses to climate: does size matter? Trees - Struct. Funct. 27, 763-772.

Carnicer, J., Coll, M., Ninyerola, M., Pons, X., Sánchez, G., Peñuelas, J., 2011. Widespread crown condition decline, food web disruption, and amplified tree mortality with increased climate change-type drought. Proc. Natl. Acad. Sci. U. S. A. 108, 1474-1478.

Carnicer, J., Domingo-Marimon, C., Ninyerola, M., Camarero, J.J., Bastos, A., López-Parages, J., Rodríguez-Fonseca, B., Lenton, T.M., Dakos, V., Ribas, M., Gutiérrez, E., Peñuelas, J., Pons, X., 2019. Regime shifts of Mediterranean forest carbon uptake and reduced resilience driven by multidecadal ocean surface temperature. Glob. Chang. Biol. https:// doi.org/10.1111/gcb.14664

Cenni, E., Bussotti, F., Galeotti, L., 1998. The decline of a Pinus nigra Arn. reforestation stand on a limestone substrate: the role of nutritional factors examined by means of foliar diagnosis. Ann. Sci. Forest. 55, 567-576.

Chen, K., Dorado-Liñan, I., Akhmetzyanov, L., Gea-Izquierdo, G., Zlatanov, T., Menzel, A 2015. Influence of climate drivers and the North Atlantic oscillation on beech growth at marginal sites across the Mediterranean. Clim. Res. 66, 229-242.

Conversi, A., Umani, S.F., Peluso, T., Molinero, J.C., Santojanni, A., Edwards, M., 2010. The mediterranean sea regime shift at the end of the 1980s, and intriguing parallelisms with other European basins. PLoS One 5, 1-15.

Cook, E.R., 1985. A Time Series Analysis Approach to Tree Ring Standardization. Dissertation. University of Arizona, Tucson, USA.

Criada-Aldeanueva, F., Soto-Navarro, F.J., 2013. The Mediterranean oscillation teleconnection index: station-based versus principal component paradigms. Adv. Meteorol. https://doi.org/10.1155/2013/738501.

Dorado-Liñán, I., Zorita, E., Martínez-Sancho, E., Gea-Izquierdo, G., Di Filippo, A., Gutiérrez, E., Levanic, T., Piovesan, G., Vacchiano, G., Zang, C., Zlatanov, T., Menzel, A., 2017. Large-scale atmospheric circulation enhances the Mediterranean east-west tree growth contrast at rear-edge deciduous forests. Agric. For. Meteorol. 239, 86-95.

Dorado-Liñán, I., Piovesan, G., Martínez-Sancho, E., Gea-Izquierdo, G., Zang, C., Cañellas, I., Castagneri, D., Di Filippo, A., Gutiérrez, E., Ewald, J., Fernández-de-Uña, L., Hornstein, D., Jantsch, M.C., Levanič, T., Mellert, K.H., Vacchiano, G., Zlatanov, T., Menzel, A., 2019. Geographical adaptation prevails over species-specific determinism in trees' vulnerability to climate change at Mediterranean rear-edge forests. Glob. Chang. Biol. 25 , 1296-1314.

Dünkeloh, A., Jacobeit, J., 2003. Circulation dynamics of Mediterranean precipitation variability 1948-98. Int. J. Climatol. 23, 1843-1866.

Enescu, C., de Rigo, D., Caudullo, G., Mauri, A., Houston Durrant, T., 2016. Pinus nigra in Europe: Distribution, Habitat, Usage and Threats. In European Atlas of Forest Tree Species; San-Miguel-Ayanz, J., de Rigo, D., Caudullo, G., Houston Durrant, T., Mauri, A., Eds.; European Commission: Luxembourg, 2016; vol. Volume 6, pp. 126-127.

Esper, J., Großjean, J., Camarero, J.J., García-Cervigón, A.I., Olano, J.M., González-Rouco, J.F., Domínguez-Castro, F., Büntgen, U., 2015. Atlantic and Mediterranean synoptic drivers of central Spanish juniper growth. Theor. Appl. Climatol. 121, 571-579.

Farjon, A., Filer, D., 2013. An Atlas of the world's Conifers: An Analysis of their Distribution, Biogeography, Diversity and Conservation Status. Brill.

Feidas, H., Noulopoulou, C., Makrogiannis, T., Bora-Senta, E., 2006. Trend analysis of precipitation time series in Greece and their relationship with circulation using surface and satellite data: 1955 - 2001. Theor. Appl. Climatol. 87, 155-177.

Fick, S.E., Hijmans, R.J., 2017. Worldclim 2: new 1-km spatial resolution climate surfaces for global land areas. Int. J. Climatol. 37, 4302-4315.

Fritts, H.C., 2001. Tree Rings and Climate. Caldwell.

Gao, X., Giorgi, F., 2008. Increased aridity in the Mediterranean region under greenhouse gas forcing estimated from high resolution regional climate projections. Glob. Planet. Chang. 62, 195-209.

Gazol, A., Camarero, J.J., Vicente-Serrano, S.M., Sánchez-Salguero, R., Gutiérrez, E., de Luis, M., Sangüesa-Barreda, G., Novak, K., Rozas, V., Tíscar, P.A., Linares, J.C., MartínHernández, N., Martínez del Castillo, E., Ribas, M., García-González, I., Silla, F., Camisón, A., Génova, M., Olano, J.M., Longares, L.A., Hevia, A., Tomás-Burguera, M., Galván, J.D., 2018. Forest resilience to drought varies across biomes. Glob. Chang. Biol. 24, 2143-2158.

Génova, M., 2000. Anillos de crecimiento y años característicos en el Sistema Central (España) durante los últimos cuatrocientos años. Boletín de la Real Sociedad española de Historia Natural 96, 33-42.

Génova, M., Fernández, A., 1998-99. Tree rings and climate of Pinus nigra subsp. salzmannii in Central Spain. Dendrochronologia 16-17, 75-86.

Génova, M., Moya, P., 2012. Dendroecological analysis of relict pine forests in the centre of the Iberian Peninsula. Biodivers. Conserv. 21, 2949-2965.
Giorgi, F., 2006. Climate change hot-spots. Geophys. Res. Lett. 33 (L08707). https://doi org/10.1029/2006GL025734.

Giorgi, F., Lionello, P., 2008. Climate change projections for the Mediterranean region. Glob. Planet. Chang. 63, 90-104.

Giovannelli, G., Scotti-Saintagne, C., Scotti, I., bioRxiv, A.R., 2019. The genetic structure of the European black pine (Pinus nigra Arnold) is shaped by its recent Holocene demographic history. BioRxiv https://doi.org/10.1101/535591.

Goubanova, K., Li, L., 2007. Extremes in temperature and precipitation around the Mediterranean basin in an ensemble of future climate scenario simulations. Glob. Planet. Chang. 57, 27-42.

Harris, I., Jones, P.D., Osborn, T.J., Lister, D.H., 2014. Updated high-resolution grids of monthly climatic observations - the CRU TS3.10 dataset. Int. J. Climatol. 34, 623-642.

Helama, S., Lindholm, M., Timonen, M., Eronen, M., 2004. Detection of climate signal in dendrochronological data analysis: a comparison of tree-ring standardization methods. Theor. Appl. Climatol. 79, 239-254.

Hijmans, R.J., Cameron, S.E., Parra, J.L., Jones, G., Jarvis, A., 2005. Very high resolution interpolated climate surfaces for global land areas. Int. J. Climatol. 25, 1965-1978.

Holmes, R.L., 1983. Computer-assisted quality control in tree-ring dating and measurement. Tree Ring Bull 43, 69-78.

Hurrell, J.W., 1996. Influence of variations in extratropical wintertime teleconnections on northern hemisphere temperature. Geophys. Res. Lett. 23, 665-668.

Hurrell, J.W., Van Loon, H., 1997. Decadal Variations in Climate Associated with the North Atlantic Oscillation. Climatic Change at High Elevation Sites. vol. 36 pp. 301-326.

Hurrell, J., Kushnir, Y., Ottersen, G., Visbeck, M., 2003. An Overview of the North Atlantic Oscillation. The North Atlantic Oscillation: Climate Significance and Environmental Impact. Geophysical Monograph vol. 134. American Geophysical Union, USA, pp. 1-36.

IPCC, 2014. In: Barros, V.R., Field, C.B., Dokken, D.J., Mastrandre, M.D. (Eds.), Climate Change 2014: Impacts, Adaptation, and Vulnerability. Part B: Regional Aspects. Contribution of Working Group II to the Fifth Assessment Report of the Intergovernmental Panel on Climate Change. Cambridge University Press, Cambridge, United Kigdom and New York, NY, USA.

Janssen, E., Kint, V., Bontemps, J.D., Özkan, K., Mert, A., Köse, N., Icel, B., Muys, B., 2018. Recent growth trends of black pine (Pinus nigra J.F. Arnold) in the eastern Mediterranean. For. Ecol. Manag. 412, 21-28.

Kassambara, A., Mundt, F., 2016. Factoextra: extract and visualize the results of multivariate data analyses.Available at. https://CRAN.R-project.org/package $=$ factoextra $(\mathrm{R}$ package version 1.0.3)

Kutiel, H., Maheras, P., 1998. Variations in the temperature regime across the Mediterranean during the last century and their relationship with circulation indices. Theor. Appl. Climatol. 61, 39-53.

Lê, S., Josse, J., Husson, F., 2008. FactoMineR: a package for multivariate analysis. J. Stat Softw. 25, 1-18.

Lebourgeois, F., Becker, M., Chevalier, R., Dupouey, J.L., Gilbert, J.M., 2000. Height and radial growth trends of Corsican pine in western France. Can. J. For. Res. 30, 712-724.

Linares, J.C., Tíscar, P.A., 2010. Climate change impacts and vulnerability of the southern populations of Pinus nigra subsp. salzmannii. Tree Physiol. 30, 795-806.

Linares, J.C., Tíscar, P.A., 2011. Buffered climate change effects in a Mediterranean pine species: range limit implications from a tree-ring study. Oecologia 167 847-859.

Luterbacher, J., García-Herrera, R., Akcer-On, S., et al., 2012. A review of 2000 years of paleoclimatic evidence in the Mediterranean. In: Lionello, P. (Ed.), The Climate of the Mediterranean Region: From the Past to the Future. Elsevier, Amsterdam, pp. 87-185.

Madrigal-González, J., Ballesteros-Cánovas, J.A., Herrero, A., Ruiz-Benito, P., Stoffel, M. Lucas-Borja, M.E., Andivia, E., Sancho-García, C., Zavala, M.A., 2017. Forest productivity in southwestern Europe is controlled by coupled North Atlantic and Atlantic multidecadal oscillations. Nat. Commun. 8, 1-8.

Maheras, P., Kutiel, H., 1999. Spatial and temporal variations in the temperature regime in the Mediterranean and their relationship with circulation during the last century. Int J. Climatol. 19, 745-764.

Maheras, P., Xoplaki, E., Kutiel, H., 1999. Wet and dry monthly anomalies across the Mediterranean basin and their relationship with circulation, 1860-1990. Theor. Appl Climatol. 64, 189-199.

Manrique, E., Fernandez-Cancio, A., 2000. Extreme climatic events in dendroclimatic reconstructions from Spain. Clim. Chang. 44, 123-138.

Martín-Benito, D., Cherubini, P., Del Río, M., Cañellas, I., 2008. Growth response to climate and drought in Pinus nigra Arn. trees of different crown classes. Trees - Struct. Funct. 22, 363-373.

Martín-Benito, D., Del Río, M., Cañellas, I., 2010. Black pine (Pinus nigra Arn.) growth divergence along a latitudinal gradient in Western Mediterranean mountains. Ann. For. Sci. 67 (401), p13.

Martín-Benito, D., Kint, V., del Río, M., Muys, B., Cañellas, I., 2011. Growth responses of West-Mediterranean Pinus nigra to climate change are modulated by competition and productivity: past trends and future perspectives. For. Ecol. Manag. 262, 1030-1040.

Martín-Vide, J., 2002. Ensayo sobre la Oscilación del Mediterráneo Occidental y su influencia en la pluviometría del este de España. vol. 1. Publicaciones de la Asociación Española de Climatología, pp. 35-42.

Meehl, G., Tebaldi, C., 2004. More intense, more frequent, and longer lasting heat waves in the 21st century. Science 305, 994-997.

Mitchell, T.D., Jones, P.D., 2005. An improved method of constructing a database of monthly climate observations and associated high-resolution grids. Int. J. Climatol. 25, 693-712.

Nehrbass-Ahles, C., Babst, F., Klesse, S., Nötzli, M., Bouriaud, O., Neukom, R., Dobbertin, M. Frank, D., 2014. The influence of sampling design on tree-ring based quantification of forest growth. Glob. Chang. Biol. 20, 2867-2885. 
Nicault, A., Alleaume, S., Brewer, S., Carrer, M., Nola, P., Guiot, J., 2008. Mediterranean drought fluctuation during the last 500 years based on tree-ring data. Clim. Dyn. 31, 227-245.

Olson, M.E., Soriano, D., Rosell, J.A., Anfodillo, T., Donoghue, M.J., Edwards, E.J., LeónGómez, C., Dawson, T., Camarero, J.J., Castorena, M., Echeverría, A., Espinosa, C.I., Fajardo, A., Gazol, A., Isnard, S., Lima, R.S., Marcati, C.R., Méndez-Alonzo, R., 2018. Plant height and hydraulic vulnerability to drought and cold. Proc. Natl. Acad. Sci. U.S.A 115, 7551-7556.

Palutikof, J.P., 2003. Analysis of Mediterranean climate data: measured and modelled. In: Bolle, H.J. (Ed.), Mediterranean Climate: Variability and Trends. Springer, Berlin, Germany.

Pasho, E., Camarero, J.J., de Luis, M., Vicente-Serrano, S.M., 2011. Impacts of drought at different time scales on forest growth across a wide climatic gradient in north-eastern Spain. Agric. For. Meteorol. 151, 1800-1811.

Piovesan, G., Schirone, B., 2000. Winter North Atlantic oscillation effects on the tree rings of the Italian beech (Fagus sylvatica L.). Int. J. Biometeorol. 44, 121-127.

R Core Team, 2018. R: A Language and Environment for Statistical Computing. R Foundation for Statistical Computing, Vienna, Austria.

Rabasa, S.G., Granda, E., Benavides, R., Kunstler, G., Espelta, J.M., Ogaya, R., Peñuelas, J. Scherer-Lorenzen, M., Gil, W., Grodzki, W., Ambrozy, S., Bergh, J., Hódar, J.A., Zamora, R., Valladares, F., 2013. Disparity in elevational shifts of European trees in response to recent climate warming. Glob. Chang. Biol. 19, 2490-2499.

Richter, K., Eckstein, D., Holmes, R.L., 1991. The dendrochronological signal of pine trees (Pinus spp.) in Spain. Tree-Ring Bull. 51, 1-13.

Rodó, X., Baert, E., Comin, F.A., 1997. Variations in seasonal rainfall in southern Europe during the present century: relationships with the North Atlantic oscillation and the El Niño-Southern oscillation. Clim. Dyn. 13, 275-284.

Rodrigo, F.S., Esteban-Parra, M.J., Pozo-Vazquez, D., Castro-Diez, Y., 1999. A 500-year precipitation record in southern Spain. Int. J. Climatol. 9, 1233-1253.

Rolland, C., 2002. Decreasing teleconnections with inter-site distance in monthly climatic data and tree-ring width networks in a mountainous Alpine area. Theor. Appl. Climatol. 71, 63-75.

Rozas, V., Camarero, J.J., Sangüesa-Barreda, G., Souto, M., García-González, I., 2015. Summer drought and ENSO-related cloudiness distinctly drive Fagus sylvatica growth near the species rear-edge in northern Spain. Agric. For. Meteorol. 201, 153-164.

Sánchez-Salguero, R., Navarro-Cerillo, R.M., Camarero, J.J., Fernández-Cancio, A., 2012. Selective drought-induced decline of pine species in southeastern Spain. Clim. Chang. 113, 767-785.

Sánchez-Salguero, R., Camarero, J.J., Dobbertin, M., Fernández-Cancio, A., Vilà-Cabrera, A Manzanedo, R.D., Zavala, M.A., Navarro-Cerillo, R.M., 2013. Contrasting vulnerability and resilience to drought-induced decline of densely planted vs. natural rear-edge Pinus nigra forests. For. Ecol. Manag. 310, 956-967.

Sánchez-Salguero, R., Camarero, J.J., Rozas, V., Génova, M., Olano, J.M., Arzac, A., Gazol, A., Caminero, L., Tejedor, E., de Luis, M., Linares, J.C., 45, 2018, 1126-1139. Resist, recover or both? Growth plasticity in response to drought is geographically structured and linked to intra-specific variability in Pinus pinaster. J. Biogeogr.

Seim, A., Treydte, K., Trouet, V., Frank, D., Fonti, P., Tegel, W., Panayotov, M., FernándezDonado, L., Krusic, P., Büntgen, U., 2014. Climate sensitivity of Mediterranean pine growth reveals distinct east-west dipole. Int. J. Climatol. 35, 2503-2513.

Shestakova, T.A., Gutiérrez, E., Kirdyanov, A.V., Camarero, J.J., Génova, M., Knorre, A.A., Linares, J.C., Resco de Dios, V., Sánchez-Salguero, R., Voltas, J., 2016. Forests synchronize their growth in contrasting Eurasian regions in response to climate warming. Proc. Natl. Acad. Sci. 113, 662-667.

Shestakova, T.A., Gutiérrez, E., Voltas, J., 2018. A roadmap to disentangling ecogeographical patterns of spatial synchrony in dendrosciences. Trees - Struct. Funct. 32, 359-370.

Stenseth, N.C., Ottersen, G., Hurrell, J.W., Mysterud, A., Lima, M., Chan, K.S., Yoccoz, N.G., Ådlandsvik, B., 2003. Studying climate effects on ecology through the use of climate indices: the North Atlantic oscillation, El Niño southern oscillation and beyond. Proc. R. Soc. B Biol. Sci. 270, 2087-2096.

Taberlet, P., Cheddadi, R., 2002. Quaternary refugia and persistence of biodiversity. Science 297, 2009-2010.

Thuiller, W., Albert, C., Araújo, M.B., Berry, P.M., Cabeza, M., Guisan, A., Hickler, T., Midgley, G.F., Paterson, J., Schurr, F.M., Sykes, M.T., Zimmermann, N.E., 2008. Predicting global change impacts on plant species' distributions: future challenges. Perspect. Plant Ecol. 9, 137-152.

Touchan, R., Garfin, G.G., Meko, D.M., Funkhouser, G., Erkan, N., Hughes, M.K., Wallin, B.S., 2003. Preliminary reconstructions of spring precipitation in southwestern Turkey from tree-ring width. Int. J. Climatol. 23, 157-171.

Vicente-Serrano, S.M., Beguería, S., López-Moreno, J.I., 2010. A multiscalar drought index sensitive to global warming: the standardized precipitation evapotranspiration index. J. Clim. 23, 1696-1718.

Walther, G., Post, E., Convey, P., Menzel, A., Parmesan, C., Beebee, T.J.C., Fromentin, J., Hoegh-Guldberg, O., Bairlein, F., 2002. Ecological responses to recent climate change. Nature 416, 389-395.

Xoplaki, E., Gonzalez-Rouco, J.F., Luterbacher, J., Wanner, H., 2003. Mediterranean summer air temperature variability and its connection to the large-scale atmospheric circulation and SSTs. Clim. Dyn. 20, 723-739. 